\title{
Adoption Attitude Towards The Usage Of Pusher Box Technology In The Rubber Industry
}

\author{
Juhaini Jabar \\ Faculty of Technology Management and Technopreneurship \\ Universiti Teknikal Malaysia Melaka \\ Mohd Haradzi Abdul Karim \\ Faculty of Technology Management and Technopreneurship \\ Universiti Teknikal Malaysia Melaka \\ Sitinor Wardatulaina Mohd. Yusof \\ Faculty of Technology Management and Technopreneurship \\ Universiti Teknikal Malaysia Melaka \\ Murzidah Ahmad Murad \\ Faculty of Technology Management and Technopreneurship \\ Universiti Teknikal Malaysia Melaka \\ Fararishah Abdul Khalid \\ Faculty of Technology Management and Technopreneurship \\ Universiti Teknikal Malaysia Melaka
}

\begin{abstract}
This study has investigated the relationship between the adoption attitude towards usage of automatic pusher box system in rubber plant industry. The study was conducted in a rubber factory under Felda Global Venture (FGV) which is located in Negeri Sembilan, Malaysia. This company strive to be the global leader in natural rubber processing offering high quality products and services through good manufacturing and eco-friendly practice. Therefore, automatic pusher box system is one of the new technologies that is used in the company. Furthermore, this automatic pusher box it is suitable for saving manual labor hours and labor costs by replacing the current semiautomated system.
\end{abstract}

Keywords: Perceived usefulness, pereived ease of use, adoption attitude towards usage, behavioral intention to use

\section{INTRODUCTION}

This research focus on adoption attitude towards usage of automated pusher box technology use behavior on Felda Rubber Industry to examine the effectiveness of automated pusher box for technology use behavior and attitude towards usage (Abu et al. 2014). Felda Rubber Industry produces natural rubber products such as latex gloves. To produce the latex gloves, first, employees in this company use manual labor to push $1500 \mathrm{~kg}$ box filled with latex. Automated pusher box technology has been introduced to help the organization to improve the performance and also reduce the problem in the workplace (Abu et al. 2015). Therefore, this research evaluates the adoption attitude toward usage of automated pusher box and relationship towards technology use behavior. According to Ajzen (1991), a person's action is determined by behavioral intentions, which in turn are influenced by an attitude toward the 
behavior and subjective norms. Arising from this motivation, several models were developed to help in predicting technology acceptance. Among these models, the Theory of Planned Behavior (TPB) (Ajzen, 1991) and Technology Acceptance Model (TAM) are widely-used and validated models.

Quality and technology are most important element to produce any products in order to satidfy the customers. Some organizations think that to purchase good machine is very costly and not worth it. The issue on this research is about automated pusher box technology adoption in a latex factory in Malaysia. Technology important to facilitate in order to improve product quality and reduce defect rate of outputs (Siti Hajar et al., 2014). Major problem faced by the organization is the less experienced worker to handle this technology (Jabar, 2011). Second, semi-automated machines frequently breaks down and experience error. Before a new technology can be adopted, organization must provide training among employees, however this will incur high cost and investment (Soosay et al., 2016). Using semi-automated machines will put organization at risk of majority employees frequently need to take medical leave or resign from their post due to back pain caused by pushing the box weighing $1500 \mathrm{~kg}$ manually. Therefore, this study examines the factors affecting adoption attitude towards the usage of automatic pusher box system in a rubber plant. This study will also evaluate the behavioral intention of employees to use the automated pusher box system.

\section{Technology Acceptance}

\section{LITERATURE REVIEW}

TAM is complementary to the innovation diffusion theory, that integrates social systems and behavioral processes involving the adoption of technology (Moore and Benbasat, 1991). Innovation diffusion theory indicates that factors such as individuals' perceptions of relative advantage, trialability, observability, complexity, and compatibility of a technology determines whether potential users will adopt the technology or not (Rogers, 2003).

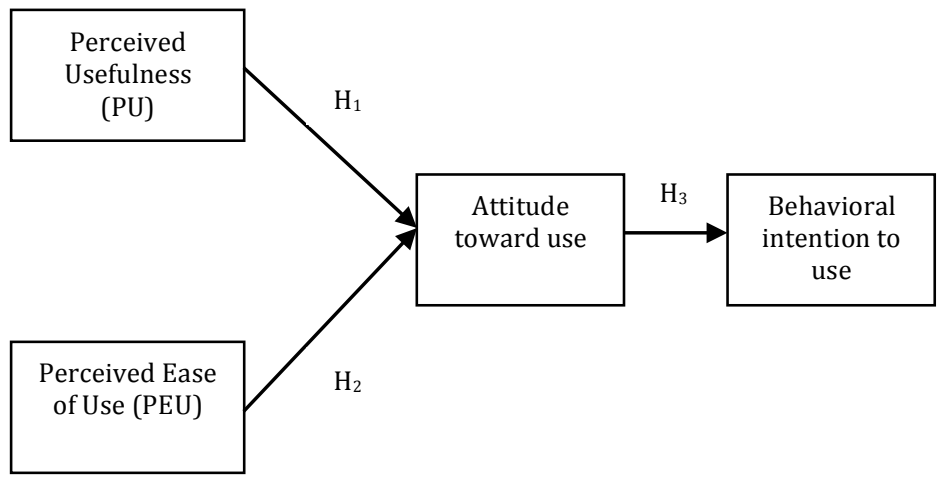

Figure 1: Theoretical framework

\section{Perceived Usefulness (PU)}

According to Teo (2009), the degree to which organization believe that using a particular system would enhance their job performance. In this case, the rubber plant top management believes that, using the systematic system like automated pusher box technology will enhance the employees performance and maintain the quality of rubber.

\section{Perceived Ease of Use (PEU)}

PEU are refers to the degree to which an the individual believes that using a particular system be free of physical and mental. In this issues, this organization believe that by using the 
automatically pusher box will be reduce the negative impact to mental and physical among of employees. Moreover, it is an advantage to the workers because they do not need to push the box weighing $1500 \mathrm{~kg}$ manually.

\section{Behavior Intention to Use}

Behavior as a person's positive or negative feeling about performing the actual behavior. Individuals perform or reproduce behavior that are themselves a product of relationships between people, their environment, and the technology that surrounds them.

\section{Attitude}

Individual's positive or negative feeling about performing the target behavior the system. There are four subs for attitude to be test using TAM such as complexity, Compatibility, Triability and Observability. Complexity is referring to the perception of difficulty of the innovation. Higher complexity as viewed by the users will lead to negative influence towards acceptance of the technology (Rogers, 2003). Compatibility of is related to the ability of users in order to use a certain technology based on their values, needs and past experience. The higher the compatibility the higher the tendency that users will adopt the technology (Chau and $\mathrm{Hu}, 2002$ ). Trialability plays an important role as users have higher inclination to adopt a technology if they are able to experience using it through free trial before actual adoption (Moore and Benbasat, 1991). Finally, when the benefit of a certain technology can be easily observed by the potential users will increase the tendency of actual adoption of the technology (Rogers, 2003). Therefore, in accordance with the related literature, this study tested the following hypotheses (please refere to Figure 1):

H1: Perceived usefulness (PU) will have a positive significant influence on Attitude towards usage (ATU) of Automated pusher box technology.

H2: Perceived ease of use (PEOU) will have a positive significant influence on Attitude towards usage (ATU) of Automated pusher box technology.

H3: Attitude towards usage (ATU) will have a positive significant influence on users' behavioral intention to use the Automated pusher box technology.

\section{Research Design}

\section{RESEARCH METHODOLOGY}

Explanatory research designs are usually structured and specifically designed to measure the characteristics described in research question. Hypotheses, derived from the theory, usually serve to guide the process and provide a list of what needs to be measured (Hair, Babin, Money \& Samouel 2003).

From the research question, the researcher developed the objectives and does the study to achieve the objectives. The research design will use an explanatory studies that shows the relationships between perceived usefulness and perceived ease of use the automated pusher box to behavior. The researcher choose the explanatory studies to understand that the research design use is relevant and easy to construct data collection. The purpose of the research in mainly descriptive and explanatory. Descriptive data has been collected through detailed questionnaire and it is also explanatory since the researcher will explain the relationship between internal factor and behavior of employees towards automated pusher box technology.

Researcher use the quantitative data collection methods rely on random sampling and structured data collection. These methods produce results that are easy to summarize, compare, and generalized (Saunders, 2012). 


\section{Research Sample}

The population and sample of this study involved 60 employees in Felda Rubber Industry under Felda Global Venture (FGV). Questionnaire was used as a tool for data collection process in this study (Sekaran and Bougie, 2010). For this study, the researchers adopted questionnaire items that were used by previous research as a reference.

\section{RESULT AND ANALYSIS}

This research focus on attitude towards usage of automated pusher box technology use behavior on Felda Rubber Industry under Felda Global Venture (FGV) to examine the effectiveness of automated pusher box for technology use behavior and attitude towards usage. Data was gathered from 60 respondents that includes all of the workers in the production line

\section{Analysis of Demographic Information of Respondent}

Table 1 depicts the gender of respondents where $73 \%$ of the respondents (44 respondents) are male and for female is a $27 \%$ (16 respondents). Table 2 illustrates that majority of respondents are $40-50$ years old with value $38.7 \%$. This is followed by $31.7 \%$ of respondent who are $30-40$ years old. Based on Table 3, the percentage that represent the experience of the respondent indicate that which observed that $36.7 \%$ respondent (22 people) have $2-5$ years experience which is similar with the number of workers with 6-10 years of experience. This is followed by $15.0 \%$ (9 people) with 11-15 years of experience.

Table 1 Respondent's Gender

\begin{tabular}{lcc}
\hline Gender & Frequency & Percentage \\
\hline Male & 44 & 73.3 \\
Female & 16 & 26.7 \\
Total & 60 & 100.0 \\
\hline
\end{tabular}

Table 2 Age of respondents

\begin{tabular}{ccc}
\hline Age & Frequency & Percentage \\
\hline $20-30$ & 12 & 20.0 \\
$30-40$ & 19 & 31.7 \\
$40-50$ & 22 & 36.7 \\
$>51$ & 7 & 11.7 \\
Total & 60 & 100.0 \\
\hline
\end{tabular}




\begin{tabular}{lll}
\multicolumn{3}{c}{ Table 3 Respondent's years of experience } \\
\hline Years of experience & Frequency & Percentage \\
\hline <1 year & 4 & 6.7 \\
2-5 years & 22 & 36.7 \\
6-10 years & 22 & 36.7 \\
11-15 years & 9 & 15.0 \\
16-20 years & 2 & 3.3 \\
>21 years & 1 & 1.7 \\
Total & 60 & 100.0 \\
\hline
\end{tabular}

\section{Reliability Test}

The measurement scales were analyzed for reliability to ensure their appropriateness before proceeding to an assessment of its validity (Hair et al., 2006). Cronbach's Alpha is used to determine the internal consistency or average correlation of the item for each independent variables components. As according to (Sekaran, 2003), the reliability that less than 0.60 are generally considered to be poor, while those in the range of 0.70 to be acceptable and those over 0.80 to be good.

Table 4 shows that the Cronbach's Alpha for the independent and dependent variables tested in this study. The purpose if this test is to check whether the data obtained is reliable or not. The rule of thumb for the reliability test is that 0.7 or higher represents good reliability and if in between 0.6 and 0.7 , the data may be acceptable. Based on the result in Table 4 , the Cronbach's Alpha for all constructs is acceptable as the values exceed .70.

Table 4 Reliability Statistic

\begin{tabular}{ccc}
\hline Construct & $\begin{array}{c}\text { Cronbach's } \\
\text { Alpha }\end{array}$ & Number of items \\
\hline Behavioral & .85 & 6 \\
Attitude & .95 & 5 \\
Perceived usefulness & .92 & 5 \\
Perceived ease of use & .81 & 3 \\
\hline
\end{tabular}

Based on the Table 5, it shows that the correlation between independent variables which are Perceived Ease of Use and Perceived Usefulness with dependent variables which are Attitude and Behaviour.

Findings from Table 5 revealed that there was a significant positive correlation between perceived usefulness and attitude towards using the system $\left(\mathrm{r}=0.924^{* *}, \mathrm{p}<0.01\right)$. This means that if employees perceived the usefulness of the system as high, then their attitudes towards using the system will also improve and vice versa. Perceived ease of use and attitude towards using the system were also found to have a strong positive correlation $\left(\mathrm{r}=0.951^{* *}, \mathrm{p}<0.001\right)$. This implies that perceived ease of use by the employees influences the attitudes towards using the system significantly. Finally, there was a significant positive correlation between attitude towards using the technology and behavioral $\left(\mathrm{r}=0.812^{* *}, \mathrm{p}<0.01\right)$. This implies that if employees have positive attitudes towards using system they will also have a positive behavior towards using the technology. 


\section{Table 5 Pearson Correlation Coefficient}

\begin{tabular}{|c|c|c|c|c|c|}
\hline CONSTRUC & & PEU & PU & Attitude & Behaviour \\
\hline PEU & Pearson & 1 & $.993^{* *}$ & $.951^{* *}$ & $.752^{* *}$ \\
\hline & correlation & & .000 & .000 & .000 \\
\hline & Sig. (2-tailed) & & 60 & 60 & 60 \\
\hline & $\mathrm{N}$ & & & & \\
\hline PU & Pearson & $.993^{* *}$ & 1 & $.924^{* *}$ & $.735^{* *}$ \\
\hline & correlation & .000 & & .000 & .000 \\
\hline & Sig. (2-tailed) & 60 & & 60 & 60 \\
\hline & $\mathrm{N}$ & & & & \\
\hline Attitude & Pearson & $.951^{* *}$ & $.924^{* *}$ & 1 & $.812^{* *}$ \\
\hline & correlation & .000 & .000 & & .000 \\
\hline & Sig. (2-tailed) & 60 & 60 & & 60 \\
\hline & $\mathrm{N}$ & & & & \\
\hline Behaviour & Pearson & $.752^{* *}$ & $.735^{* *}$ & $.812^{* *}$ & 1 \\
\hline & correlation & .000 & .000 & .000 & \\
\hline & Sig. (2-tailed) & 60 & 60 & 60 & \\
\hline
\end{tabular}

\section{Hypotheses testing}

The attitude towards usage of automated pusher box technology was tested with the predictors of perceived usefulness and perceived ease of use using multiple regression. The overall model was significant, $F(1,58)=340.35, p<.001$, and counted $85.4 \%$ variability in support for attitude towards usage. Perceived ease of use was the stronger predictor of the two factors where, $\beta=2.47, t(60)=8.46, p<.001$, thus, the perceived ease of use has impact between attitudes towards usage of automated pusher box technology. Perceived usefulness was also significant in predicting attitude towards usage, $\beta=1.53, t(60)=5.24, p<.001$ (see Table 6). Attitude towards usage was also significant to predict behavioral intention to use the automated pusher box technology, $F(1,58)=111.93, p<.001$, however it only counted $65.9 \%$ variability. Therefore, all three hypotheses tested in this research were accepted (see Table 7).

Table 6 Regression results of PU and PEU and attitude towards usage

\begin{tabular}{lrrrrr}
\hline Predictor & $\mathrm{B}$ & SE B & $\beta$ & $\mathrm{t}$ & $\mathrm{P}$ \\
\hline PU & 1.20 & .23 & 1.53 & 5.24 & .00 \\
PEU & 2.09 & .25 & 2.47 & 8.46 & .00 \\
\hline
\end{tabular}

Dependent variable: Attitude towards using

Table 7 Regression result of attitude towards usage and behavior intention

\begin{tabular}{lcrrrr}
\hline Predictor & B & SE B & $\beta$ & $t$ & P \\
\hline Attitude & 1.35 & .13 & .81 & 10.58 & .00 \\
\hline Dependent variable: Behavioral Intention & & & &
\end{tabular}

\section{CONCLUSION AND RECOMMENDATION}

This research is about the adoption attitude towards usage of pusher box technology use behavioral in Felda Rubber Industry, Negeri Sembilan, Malaysia. Overall, it can be conclude that there are some influences of attitude towards usage using the automated pusher box system in workplace. The TAM model is strongly supported in workplace environment, the influence of the perceived ease of used on attitude towards usage is very strong as well as the attitude towards using on the behavioral intention to use automated pusher box technology.

There was a strong positive correlation between attitude towards usage and behavioral intention to use of the automated pusher box system. This implies that employee's behavioral intention to use the system changes positively and is likely to improve to an extent. These 
findings are consistent with previous research in the Malaysian context (see for example: Abu et al. 2015; Abu et al. 2014) whereby an individual's behaviors to use a system will reflect their use intentions. Therefore this study has confirmed that behavioral intention of employees in Felda Rubber Industry to use the pusher box will determine the actual technology to be used to replace the semi-auto machine.

The finding has illustrate a strong significant positive relationship between all usefulness variable (perceived usefulness and perceived ease of use) the finding of this study. When employees perceived the new technology as applicable, flexible and interactive the employees will have positive behavioral and attitude towards using the technology. The usefulness construct analysed how employees view the benefit of using the automated pusher box in their organisation. Moreover, ease of use higlights whether it is "cost" effective to utilise the new technology fro the perspective of the user. The findings of this study comfirms that once employees view a technology to be useful, the behavioral intentions to adopt the technology will be enhanced (Pikkarainen et al. 2004). Percieved usefulness is an important determinant for a technology to be successfully adopted by employees of a certain organisation (Abu et al. 2014).

Results revealed that perceived usefulness, perceived ease of use, attitude combined are significant predictors of behavioral intention to use. These findings are also consistent with previous studies whereby percieved ease of use and percieved usefulness give direct and indirect impact towards bahavioral intention (Agarwal \& Karahanna, 2000; Vankatesh \& Davis 2000). It is acknowledged that employees intention to use the pusher box technology have a critical impact on technology use behavior. The new technology will ensure the organization to experience higher returns in terms of output as well as higher social well-being among the employees as they will minimise work injury when using the technology. The more accepting the employees of the automated pusher box system, the more willing they are to make changes in terms of time and effort to use the system. This will also lead to sustainable manufacturing practice as the safety of workers are taken care of and organisation may produce their output in a shorhet production time (Soosay et al. 2016).

\section{RECOMMENDATIONS}

Based on the result of this study, recommendations are suggested that should help to improve the production line process. The recommendation does not solely apply to the studied organization but to all organizations in Felda Rubber Industry that are committed to technological competitiveness. In light of the research finding, the following recommendations are made. First, Felda Rubber Industry should undertake a deliberate funding to develop and adopt technological innovations that are perceived useful and easy to use by their employees so as to foster significant behavioral intention to use. Second, Felda Rubber Industry; which has embraced technological innovation by focusing on changing employees' needs and want, should give high priority in creating a safe working environment that takes care of the social well-being of their employees. Finally, Future qualitative research on technology adoption could be carried out to uncover other factors that may determine the acceptance and adoption of new technology in a particular organization. The future study should focus on the views by both the employees as well as the top management in order to gauge the overall understanding on technology decision in organizations. 


\section{Reference}

Abu, F., Jabar, J., \& Yunus, A. R. (2015). Modified of UTAUT Theory in Adoption of Technology for Malaysia Small Medium Enterprises (SMEs) in Food Industry. Australian Journal of Basic and Applied Sciences, 9(4), $104-109$.

Abu, F., Yunus, A. R., Majid, I. A., Jabar, J., Aris, A., Sakidin, H., \& Ahmad, A. (2014). Technology Acceptance Model (TAM): Empowering Smart Customer To Participate in Electricity Supply System. Journal of Technology Management and Technopreneurship, 2 (1), 85-94.

Ajzen, I., \& Fishbein, M. (1980). Understanding Attitudes and Predicting Social Behavior. Englewood Cliffs, NJ: Prentice-Hall Inc.

Ajzen, I. (1991).The Theory of Planned Behavior. Organizational Behavior and Human Decision Processes, 50,179211.

Al-Gahtani, S. (2001). The applicability of TAM outside North America: An empirical test in the United Kingdom. Information Resources Management Journal, 14(3), 37-46.

Bagozzi, R, P. (2007). The legacy of the technology acceptance model and proposal for a paradigm shift. Journal of the Association for information systems, 8(4), 244-254.

Chuttur M.Y. (2009). "Overview of The Technology Acceptance Model: Origins, Developments and Future Directions," Indiana University, USA .Sprouts: Working Paperson Information Systems, 9(37).

C. M. Gomes and I. Kruglianskas. Management of External Sources of Technology Information and Innovation Performance. International Journal of Innovation and Technology Management, (vol.6) (no.1-4).

Chau, P.Y.K., and P.J. Hu (2002) "Examining a Model of Information Technology Acceptance by Individual Professionals: An Exploratory Study" Journal of Management Information Systems 18(4), pp. 191-229.

Chau, P.Y.K., and P.J. Hu (2002) “Investigating Healthcare Professionals' Decisions to Accept Telemedicine Technology: An Empirical Test of Competing Theories” Information and Management 39, pp. 297-311.

Davis F.( 1989): Perceived Usefulness, Perceived Ease Of Use, And User Acceptance Of Information Technology. MIS Quarterly, Vol. 13 318-341

Davis, F. D. (1989). Perceived Usefulness, Perceived Ease of Use, and User Acceptance of Information Technology. MIS Quarterly, 13(3), 319-339.

David, A. K. (1998). Multiple Factor Models. Retrieved May 14, 2015 from http://davidakenny.net/cm/mfactor.htm

Davis Fred, D (1993). User Acceptance Of Information Technology: System Characteristics, User Perceptions And Behavioral Impacts Int. J. Man-Machine Studies (1993) 38, 475-487

Eiker, J.K., and Sindi, A.A., (1997). User Acceptance of Expert Systems: A Test of the Theory of Reasoned Action. Journal of Engineering and Technology Management, 142 (2) 147-173

Fishbein, M., \& Ajzen, I. (1975). Belief, Attitude, Intention and Behaviour: An Introduction to Theory and Research. Reading, MA: Addison-Wesley.

Gefen, D. \& Straub, D. (2000). The Relative Importance of Perceived Ease of Use in IS Adoption. Journal of the Association for Information Systems Vol. 1(8)

Hair, J., R. Anderson, Tatham, R. and Black, W., 1998. Multivariate Data Analysis. Prentice Hall, New Jersey.

Jabar, J. (2012). Strategic technology alliances, technology transfer and the performance of Malaysian manufacturer. Journal of Engineering and Technology, 69-98.

Jagdeep, S., \&Harwinder, S. (2012). Continuous Improvement Approach: State-of-Art-Review and Future Implications, 3(2), 89.

Lee, Y ounghwa; Kozar, Kenneth A.; and Larsen, Kai R .T. (2003)."The Technology Acceptance Model: Past, Present, and Future, "Communications of the Association for Information Systems: Vol. 12, Article 50. Retrieved April 25, 2015 from http://aisel.aisnet.org/cais/vol12/iss1/50

Lewin, G.W. (Ed.) (1948). Resolving Social Conflicts. New York, NY: Harper \& Row. (Collection of articles by Kurt Lewin) 
Siti Hajar, M., Norfaridatul Akmaliah, O., Juhaini, J., \& Izaidin, A. M. (2014). Customer relationship management practices: the impact on organizational performance in SMEs of food manufacturing industry. European Journal of Business and Management, 35-48.

Moore, G. C. \& Benbasat, I. 1991. Development of an instrument to measure the perceptions of adopting an information technology innovation. Information Systems Research. Vol. 2(3), pp. 192-222.

Moore, G.C. and Benbasat, I., 1991. Development of an instrument to measure the perceptions of adopting an information technology innovation. Information Systems Research, 2,192-222.

Morris, M. G., \& Venkatesh, V. (2000). Age differences in technology adoption decisions:Implications for a changing work force. Personnel Psychology, 53(2), 375-403.

Mathieson,K., E. Peacock, and W.W. Chin (2001) “Extending the Technology Acceptance Model: The Influence of Perceived User Resources” Data Base 32(3), pp. 86-112.

Rogers, (2003). Rogers, E.M., 1995. Diffusion of Innovations, 4th Edition. The Free Press, New York.

Shroff, R. H., Deneen, C. D. \& Ng, E. M. W. (2011). Analysis of the Technology Acceptance Model in Examining Students' Behavioural Intention to Use an E-Portfolio System. Australasian Journal of Educational Technology, 27(4), 600-618. Retrieved May 10, 2015 from http://www.ascilite.org.au/ajet/ajet27/shroff.html

Soosay, C., Nunes, B., Bennett, D. J., Sohal, A. S., Jabar, J., \& Winroth, M. (2016). Strategies for sustaining manufacturing competitiveness Comparative case studies in Australia and Sweden. Journal of Manufacturing Technology Management, 27(1), 6-37. https://doi.org/10.1108/JMTM-04-2014-0043

Tan, M. \& Teo, T. S. H. 2000. Factors influencing the adoption of Internet banking. Journal of the Association for Information Systems. Vol. 1 (5), pp. 1-42.

Teo, T. (2009). Modelling technology acceptance in education: A study of pre-service teachers.Computers \& Education, 52(2), 302-312. http://dx.doi.org/10.1016/j.compedu.2008.08.006

Teo, T. \& van Schalk, P. (2009). Understanding technology acceptance in pre-service teachers: A structuralequation modeling approach. The Asia-Pacific Education Researcher, 18(1), 47-66.

Venkatesh, V., Davis, F. (2000). A theoretical extension of the technology acceptance model: four longitudinal field studies. Management Science,46(2), 186-20 